\title{
Recognition of Prior Learning: Are We Bridging the Gap between Policy and Practice in the Workplace?
}

\author{
Mary-Jane Makeketa
}

1096 Rhifumo Street, Block DD, Soshanguve, 0152

Mary-Jane.Makeketa@eskom.co.za

Mncedisi C. Maphalala

University of South Africa, College of Education: Department of Curriculum \& Instructional Studies, 0003, Pretoria, South Africa

E-mail:mphalmc@unisa.ac.za

Doi:10.5901/mjss.2014.v5n1p249

\begin{abstract}
The study examines the implementation of recognition of prior learning (RPL) in the workplace, its effectiveness and impact on improving the lives of the previously disadvantaged groups and its contribution towards enhancing a culture of lifelong learning in South Africa. The Northern Region of the Eskom Distribution was used as a case for the purposes of this study. The study adopted a mixed method research approach in which a questionnaire was administered to a randomly selected sample of 242 employees. In addition, interviews were conducted with three purposively selected (information rich) participants. The findings reveal that Eskom has policies and guidelines on RPL and a clearly stipulated purpose which is in line with the National Qualifications Framework (NQF), however, the current RPL policies and procedures have not been piloted within the Northern Region, the information has not yet reached everyone in the business, and employees' level of awareness is still low. Findings also reveal that RPL does exist in Distribution and efforts to implement it are traceable. A number of milestones and achievements are noted in the business as a whole as well as in the region, although a lot still needs to be done to ensure full and effective implementation. The last finding shows that there are a number of gaps and challenges impeding the success of RPL. These range from capacity building to quality assurance. On the basis of the findings, a number of recommendations to strengthen the RPL practice in the workplace are proposed and suggested.
\end{abstract}

Keywords: Lifelong learning, informal learning, non-formal learning, assessment

\section{Introduction}

Recognition of prior learning has been used in vocational and non-formal education for a long time and is common practice in higher education in many countries. The shift in this research is from a 'higher education mentality' to the workplace, where most adult learning takes place. Learner-centred practices are grounded in a humanistic approach to adult education that sees adults as "autonomous, holistic beings, whose accumulated life experience provides a foundation for their learning" (Cretchley \& Castle, 2001:487). Adult learning covers all types of learning by adults who have left initial education and training, however far that process went and for whatever reasons; and includes learning for personal, civic and social purposes, as well as for employment-related purposes. Breier and Ralphs (2009) refer to 'practical sense', 'practical wisdom', 'moral knowledge' and 'practical knowledge', which are dependent on experience. Hence, one cannot divorce adult learning and experience from RPL. Chappell (cited by Keating, 2006) comments that working knowledge is "rarely codified in text books, formal training programs, competency standards or procedures manuals" and is more likely to be developed within the context and environment of the immediate workplace. It is this 'working knowledge' that academic institutions are seeking through programmes such as Learning in the Workplace (LiW), work-based/work-integrate learning (WiL), internships, work experience, in-service training, learnerships, apprenticeship, and other forms of learning in which learners or students are given time in their study programmes to engage in the workplace. Groenewald and Thulukanam (2005) acknowledge that certain learning outcomes or competencies are best (or could 'only' be) acquired through real-life workplace experiences, and that this learning requires facilitation, direction and guidance through mentoring.

The workplace is increasingly seen as a legitimate site for learning in formal education programmes, with changes 
in the economy stimulating a "greater focus on work and workplaces as significant sites for learning" (Keating, 2006:2), in all educational sectors. A number of drivers for this increased emphasis include concern across the sectors to improve the preparation of students for the world of work, an on-going concern with bridging the gap between theory and practice, and a related increase in emphasis on generic capabilities and lifelong learning capabilities. These changes affect not only school leavers but also existing workers and adult learners. The need for all workers to maintain their employability in a climate of increasing change is well documented, with Keating (2006) reporting that South Africans, like Australia's workforce, are aging, thus there is an increasing need to keep skills current and relevant while they continue working.

The labour market is central because it is a place for the production of non-formal and informal learning situations. Employers in all countries are quick to point out that the most important non-formal and informal learning probably takes place at work. This is crucial in explaining why they logically often demand more direct involvement in devising the standards used in a recognition process, especially if it leads to certified qualifications.

Many South Africans may not have formal qualifications, however, they have the necessary skills to perform their jobs competently. RPL, acknowledged by the National Qualifications Framework (NQF), provides such individuals with the means to obtain formal recognition for the experience and skills gained outside formal education. According to the South African College for Open Learning, RPL or the Accreditation of Prior Learning (APL) is an acceptable method of certification or exemption:

\begin{abstract}
"APL is a process that enables people of all ages, backgrounds, and attitudes to receive credit for achievements they have acquired outside the classroom. The basic premise of APL is that individuals can and do learn through their lives in a variety of settings and that often the ensuing skills, knowledge and abilities are equal and frequently superior to those obtained by students following traditional routes through formal education" (Moore \& van Rooyen, 2002:294).
\end{abstract}

Through the process known as RPL an individual can potentially have his or her workplace and personal life learning assessed and matched to the requirements of a qualification. If the assessor judges that they do then the registered assessor and accredited provider may award the individual the full or partial qualification. However, the process is far from simple, as Deller (2004) cautions.

There is a definite need to form a link between knowledge, experience, learning and qualifications. This link should benefit everyone involved equally. The workplace needs to pay attention to employees with extensive practical experience but limited or no formal qualifications. In its declaration in the Congress of South African Trade Unions Education and Skills Conference (COSATU, 2009), the union group maintains that citizens must overcome the divide between mental and manual labour and address the imbalances of the past through Early Childhood Development (ECD), RPL, adult basic education and training (ABET), career-pathing and related strategies.

The present study examines whether recognition of prior learning (RPL) is being implemented in the workplace, its effectiveness and impact on improving the lives of the previously disadvantaged groups and its contribution towards enhancing a culture of lifelong learning in South Africa.

This paper therefore sought to answer the following questions:

- What is the level of awareness about RPL among employees in the Eskom Northern Region?

- What are the trends and practices in the implementation of RPL in the workplace?

- What are the gaps and challenges in implementing RPL in the workplace?

- How can the RPL processes and practices be strengthened?

\title{
2. Research Methodology
}

This study adopts a mixed method approach in the data collection process. Mixed-method research is the combination of quantitative and qualitative methods and analyses in a single study. Creswell in Maree (2007:261) defines it as "a procedure for collecting, analysing and mixing both types of data at some stage of the research process within a single study, to understand a research problem more completely". A questionnaire was administered to a randomly selected sample of 242 employees. In addition, interviews were conducted with six purposively selected (information rich) participants who occupy managerial positions. Interviews in this study were used as a follow-up to the questionnaire, as well as to provide more details about the quantitative data collected.

Data analysis in mixed methods research consists of analysing separately the quantitative data using quantitative methods and the qualitative data using qualitative methods. It also involves analysing both sets of information using techniques that mix the quantitative and qualitative data and results, namely the mixed method analysis (Creswell \& Clark, 2011). In this study, both data analysis procedures were used to make sense of the collected data. The 'interactive 
continuum' strategy (Newman \& Benz, 1998) was applied and data analysis occurred both within and between the quantitative (descriptive analysis) and the qualitative (description and thematic text).

Since the study adopted a mixed method research approach, mean scores and ANOVA were computed to determine the statistical significance of differences between them. Themes were generated from the sections of the questionnaire, and compared with the results obtained from the interviews with different respondents. Cross-tabulation was also used to investigate patterns or possible relationships in the data

According to Creswell and Clark (2011), when analysing data, researchers go through a similar set of steps for both quantitative and qualitative data analysis, namely, preparation, exploration, analysis, representation, interpretation, and validation

\section{Findings}

This section is arranged by first grouping the interpreted findings thematically and then discussing the themes under the relevant research questions.

\subsection{Knowledge, understanding and awareness on RPL}

Research question 1: What is the level of awareness about RPL among employees in the Northern Region?

\subsubsection{The purpose of RPL}

This question was raised in order to check the level of awareness about RPL among employees in the Northern Region. From the findings, the analysis of the data revealed much uncertainty among employees in the Northern Region distribution. For instance, on the one hand, 59.8\% respondents admitted to knowing about RPL and 56\% having attended a workshop/presentation, while on the other hand only $40.2 \%$ agreed to understanding the aim and purpose of RPL. Moreover, qualitative findings also highlighted lack of information of RPL. In contradiction to $59.8 \%$ admitting to knowing about RPL and 56\% having attended a workshop/presentation, the majority were still not sure about the purpose or aims of RPL. It must be noted that among the 19.3 responses that indicated having been gone through RPL processes it was actually done by outside institutions not as an Eskom initiative. In total, 79.8 of the respondents have not been RPL'ed. From the literature review in particular, Eskom policies and guidelines on RPL (Eskom 2007; Eskom 2010), there is a clear stipulated purpose which is in line with the NQF. Qualitative responses also highlighted the government's mandate for the business to recognise and credit people with skills, experience and knowledge, but without qualifications. However, it is evident that the information has not yet reached everyone in the business.

\subsubsection{Benefits and advantages of RPL}

The benefits of RPL cannot be overlooked. Both the Literature review, including national policy documents and Eskom procedures (Eskom 2007), have demonstrated the importance of RPL and its benefits to all stakeholders. These vary from promotion of a lifelong learning culture, as encouraged by the National Education Policy Act (no. 27 of 1996), to providing excellent prospects for the individual, companies and society in general, as noted by the Danish Government policy paper on RPL (2005). Learning, as noted by the OECD, whether it is recognised through formal credits towards qualifications or by other means, is important in meeting the career, social and personal aspirations of individual learners (Grunning et al, 2008:2). Furthermore, beyond the needs of individuals, the establishment of systems of non-formal and informal learning also has the potential to enrich the social, economic and cultural well-being of the country.

From the findings, it is evident that respondents agreed that once candidates have been RPL'ed and certified they have a better chance when applying for higher positions for which they did not qualify before (i.e., career mobility). One other benefit for individual employees and employers is cost- and time-effectiveness, to which even the literature review bore witness. Authors maintain that RPL reduces the time learners have to spend in training (Moore \& van Rooyen, 2002). It is upheld in the national principle that a recognition procedure should be cheaper than the corresponding fulltime formal programme (Werquin, 2010). However, benefits such as salary increase, car and cell phone allowances and promotion could not be backed up or substantiated. There seemed to be a sense of uncertainty or commitment from top management and not even the policy addresses any connections of RPL qualification and the remuneration strategy. Again, the Eskom RPL procedure (Eskom 2007) does not include promotion as one of SAQA's purposes. 


\subsubsection{Marketing strategies}

From the findings, marketing emerged as the most powerful tool in creating and promoting RPL awareness among employees. The sub-theme of marketing strategies emerged while checking on the level of awareness among employees. In the survey, this was covered to check the percentage who had attended a workshop or presentation on RPL. From the responses, only $2.6 \%$ strongly agreed to having attended while $36.6 \%$ strongly disagreed. Findings indicated an urgent need for awareness to be intensified amongst employees. This is in spite of the positive responses from the interviewees about the road show, campaigns and presentations held to date in the region. Again, from the above, it is evident that vigorous and visible marketing strategies have to be embarked upon to raise the level of awareness among employees and to ensure 100\% coverage even to the field worker, bearing in mind that not all employees are computer literate. As confirmed by national and regional RPL coordinators, many areas in the region still need to be provided with the opportunity to attend workshops and be covered by campaigns. The cries and calls from employees for information and communication as recorded in the analysis/findings cannot be over-emphasised. It is crucial for the Northern Region of Eskom to embark on vigorous RPL campaigns and promotion. It must be noted that in those regions where awareness campaigns were radical the results were significant.

\subsubsection{Policies, procedures and guidelines}

It was noted in the literature review that much work has already been done in the country in terms of developing RPL policies and implementing it from the SAQA Act to the National education policy. Grunning et al (2008) also reported that recognition of non-formal and informal learning is now high on the policy agenda in many OECD countries. Eskom can be applauded for having policies, procedures and guidelines governing the implementation of RPL in place as part of its skills development, from the national level to all its regional and operational structures (Dx, Gx, Tx, Corporate and head office). It is within these policies and guidelines that the RPL process and assessment processes were drawn and stipulated.

The findings show that these policies exist, however, $36.8 \%$ of respondents agreed to them being readily available, while $63.2 \%$ disagreed. It is evident from the findings that the current RPL policies and procedures had not been piloted, as one of the respondents claimed. Hence the emergence of calls from respondents for "clear guidelines and standards", "the company to develop and implement policies and procedures for RPL" and "Policies and guidelines of RPL must be communicated to employees" as noted from various responses. It is evident from the findings that it is one thing to have policies and another thing to have them readily available and accessible to people on ground level, as well as to have them implemented. This was also confirmed by research findings from the University of Pretoria, that the current RPL policy has not yet achieved its objective as a mechanism to address issues of social justice. Nor has it substantially increased the participation rate of historically disadvantaged students. This confirmed that good policy intentions do not necessarily lead to good practice.

\subsection{Trends and practices in the organisation:}

\section{Research question 2: What are the trends and practices in the implementation of RPL in the workplace?}

\subsubsection{Support strategies}

It is evident from the findings that from top management at national and divisional level there is support and governance in the running of RPL in Eskom. However, according to the quantitative findings, the majority of employees are not receiving enough support, for example, $43.4 \%$ disagreed that there were support structures in place, as opposed to $28.1 \%$ who agreed. Again, 39.3\% disagreed that management fully supported and promoted RPL in their sections as opposed to $29.8 \%$ who agreed and $24 \%$ who disagreed with senior management's convictions, as opposed to $9.4 \%$ who strongly agreed. It also emerged that the lack of management involvement, support and monitoring of RPL in respective departments and sections is a serious challenge in the region and the focus to address it must be expedited. Qualitative findings also indicated that although support does exist, it is not adequate and needs to be worked on. The challenge of services and support emerged as one of the findings in the study conducted by Kizito (2006). 


\title{
3.2.2 RPL integration with IDP and further studies
}

This relates to the current training and development paths. Findings confirmed that RPL does not exist in isolation but supports and is integrated with other programmes for the development of employees in Eskom. The data confirms that there is integration between the IDP, further studies and RPL. $74.8 \%$ of the participants agreed to the IDP contributing towards their professional growth and development, while only $10.3 \%$ strongly disagreed. Interviewees' responses also confirmed the link and integration of employees' development practices, as noted in below statements:

\begin{abstract}
... there is a very big link between the two, ... by identifying those skills gaps we put them in the IDP so that a person should go and do those courses...

The results of RPL... will actually tell us or the candidate what is that s/he has acquired, in terms of the level of qualification. ... if you have an IDP, those gaps identified, can be closed through not necessarily through further studies only, but through skills programmes, learnerships, short courses and many other courses including Further studies.
\end{abstract}

\subsubsection{The regional progress picture}

Findings reveal that the Northern Region's RPL performance is still in its early stages. It was evident in the findings that some of the factors that contributed towards this slow progress were, inter alia, inconsistency in HRD management, lack of registered qualifications or unit standards against which to assess candidates, as well as other projects which took top priority in the business. However, some efforts have been underway. The milestones achieved thus far, as recorded in the findings, include issues such as staff development and training, target areas identified, other projects completed, and training management in place. With these achievements there is hope that the end of the year 2013 will see significant progress. Regarding the above theme, the literature review such as SAQA (2002), Department of Education, (1998b) Werquin (2010) etc, confirmed that RPL exists in South Africa. The critical question was whether this had been filtered down through the education system and the workplace. Survey questions ranged from finding out when RPL was introduced, and how it related to other employees' development practices in the workplace, for example, IDPs, further studies and skills programmes. It is evident from the findings that RPL does exist and efforts to implement it are visible/traceable, not only in HET and FET but even in the workplace and in Eskom particularly. As reflected in the quantitative survey and through the interview responses, it is apparent that much still needs to be done, as evident in the following four sub-themes.

On a positive note, the following milestones from the findings are worth noting: the region has 10 registered assessors, three available moderators, and 10 trained RPL advisors. It is ready to take up the RPL project for the business.

\subsection{Gaps and challenges}

Research question 3: What are the gaps in the implementation of RPL in the workplace?

A number of gaps and challenges impeding the success of RPL were highlighted by various authors (Deller, 2004; Kizito, 2006; Maboye, 2011; Cretchley \& Castle, 2001; SAQA, 2004) in the literature review. These ranged from capacity building and funding to quality assurance. In this study however, gaps and challenges revolved around policies and procedures, proper control systems and information. Furthermore, findings from interviews indicated that there were challenges with regards to training of staff, registered unit standards and qualifications, standardised assessment tools, and lack of support from management.

According to SAQA, planning for staff development is critical for the success of RPL in an institution or workplace. The SAQA RPL policy is explicit on the need for the training of qualified and registered practitioners (SAQA, 2004). SAQA further maintains that the implementation of RPL will require the allocation of specific roles and duties and the development of expertise in this area of provisioning (SAQA, 2004).

\subsection{Recommendations to strengthen the RPL practice in the workplace}

\section{Research question 4: How can the RPL processes and practices be strengthened?}

A number of suggestions were raised by respondents in this section. Suggestions and recommendations made ranged from aspects and issues of promotion and marketing to calls for management support. While addressing emerging trends and challenges in RPL in South Africa, in the literature not only were challenges highlighted but 
solutions and lessons learnt from other countries were shared. The research question here needed to address ways in which the RPL practice can be strengthened in the workplace to ensure its successful and effective implementation. In this study, question probing this aspect was open-ended and respondents were asked to say what they thought should be done to strengthen the RPL practice in the workplace. Responses were on different aspects of RPL, these highlighted amongst other things awareness workshops, personal assistance, regular visits, helping the RPL candidate to put the file together, and sufficient capacity to drive RPL exhibitions.

\subsubsection{The future of $R P L$}

The quantitative findings have revealed a high level of enthusiasm among Northern Region employees for RPL. For example, when asked whether they would like to be RPL'ed in the future, in principle $86.8 \%$ agreed while only $23,1 \%$ disagreed. This shows that a high percentage believe in the potential of RPL. Qualitative findings also showed interviewees' optimistic and positive opinion about the future of RPL. They saw it as being successful in fulfilling its purpose of opening opportunities for workforce empowerment and transformation in the future, with $100 \%$ coverage in the region.

\section{Conclusion}

The results of the study led to the following conclusions:

- The level of awareness about RPL among employees in the Northern Region is very low.

- The trends and practices in the implementation of RPL in the workplace indicate that policies and guidelines are there but not readily accessible or well communicated.

- There are a number of gaps in the implementation of RPL in the workplace.

- Suggestions and recommendations from respondents show that the RPL processes and practices can be strengthened.

The researchers' conclusion, on the basis of the findings, is that although there is an effort by the government and Eskom to foster a culture of learning in the workplace through RPL, very little progress has been made in implementing meaningful RPL in the Northern Region. Again, a number of employees are still not yet aware or up to date with RPL and how it can benefit them. There is an urgent need to have this effort transferred from a debate of ethos into a practical, workable and understandable process which will benefit all stakeholders. As one respondent commented, "... stop preaching it, do it'.

Finally, the national objective of transforming the society through access, redress, training and empowerment opportunities, as well as career paths, can be achieved through RPL. However, it takes two to tango, but in this case, it takes three to reassert the value of RPL in the workplace: - the government, the employer and the employee.

\section{References}

Andersson, P. 2008. National policy and the implementation of recognition of prior learning in a Swedish municipality. Journal of Education Policy,23(5):515-531.

Breier, M. 2005. A disciplinary-specific approach to the recognition of prior informal experience in adult pedagogy: 'rpl' as opposed to 'RPL'. Studies in Continuing Education, 27(1):51-65.

Breier, M. \& Ralphs, A. 2009. In Search of Phronesis: Recognizing Practical Wisdom in the Recognition (Assessment) of Prior Learning. British Journal of Sociology of Education, 30(4):479-493.

COSATU. 2002. 'Learning and Work RPL, Steps to Implement RPL', Recognition of Prior Learning on the NQF (abstract). Pretoria. Readings on Purpose Reading 1c. Available from: http://www.nqf.org.za/download_files/help-box/M7_RPL_Readings.pdf. (Accessed 7th June 2011).

Cosatu. 2009. Education and Skills Conference. Johannesburg Open Learning, (25)2:153-161.

Creswell, J.W.2003. Research Design. Qualitative, Quantitative, and Mixed Methods Approaches. 2nd Ed. Thousand Oaks, Ca: Sage. Creswell, J.W. 2009a. Educational Research: Planning, Conducting, and Evaluating Quantitative and Qualitative Research. USA: Sage. Creswell, J.W. 2009b. Research Design. Qualitative, Quantitative, and Mixed Methods Approaches.3rd Ed. Thousand Oaks, Ca: Sage. Creswell J.W. \& Clark V.L. 2011. Designing and Conducting Mixed Methods Research. 2nd Ed.. USA: Sage.

Cretchley, G. \& Castle, J. 2001. OBE, RPL and Adult Education: Good Bedfellows In Higher Education in South Africa? International Journal of Lifelong Education, 20(6):487-501. (accessed on 20th August 2011).

Deller, K. 2004. How to Implement RPL in The Workplace. South Africa: Knowres.

Department of Education. 1995. White Paper on Education and Training. Notice 196 of 1995. Available from: 
http://www.education.gov.za/ (accessed on 31st January 2011).

Department of Education. 1997. Education White Paper 3: A Programme for the Transformation of Higher Education, Notice 1196 of 1997. Pretoria: Government Gazzette No. 18207.

Department of Education. 2001. National Plan for Higher Education. Pretoria.

(Department of Higher Education and Training, (2010). Available from http://www.dhet.gov.za/SearchResults/tabid/37 /Default.aspx?Search=recognition+of+prior+learning. (accessed 11 th February 2011).

Eskom Academy of Learning (EAL). 2011. Learner Guide: Assess Employee - Manage Recognition of Prior Learning. Eskom Holdings Soc Limited. Midrand.

Eskom. 2007. Recognition of Prior Learning Procedure (final draft). Available from. Eskom intranet. (accessed 12th November 2010).

Eskom. 2010. Standardised Training Processes in Eskom Distribution Procedure (draft 0.1). Available from: Eskom intranet. (accessed $12^{\text {th }}$ November 2010).

Grunning, D., Van Kleef, J. \& Werquin, P. 2008. Recognition of Non-formal and Informal Learning: Country Note for South Africa, OECD, Paris, available at www.oecd.org/edu/recognition. (accessed on 19th August 2011).

Hannan, A. 2011. Beginning Research. Faculty of Education, University of Plymouth. available from www.edu.plymouth.ac.uk/resined /beginning/begresed.htm (accessed on $26^{\text {th }}$ October 2011)

Hannan, A. 2007. How to Use Interviews in Education Research. Faculty of Education, University of Plymouth. Available from: http://www.edu.plymouth.ac.uk/resined/interviews/inthome.htm. (accessed on 26th October, 2011).

Heyns, J. P. 2004. Recognition of Prior Learning (RPL): In Search of a Valid and Sustainable Mechanism for South Africa. Published Dissertation. University of Pretoria Etd. Available from http://upetd.up.ac.za/thesis/available/etd-12062004-131217/. (accessed on August 18, 2011).

Keating,S. 2006. Learning in the Workplace: A Literature Review Post Compulsory Education Centre. Victoria University. Available from: tls.vu.edu.au > vu college > liwc ; (accessed on the 20th August 2011).

King, M. 2003. RPL Policies and Practices: Reality Challenges: Paper Presented At The 2nd National Jet RPL Conference of July 2003. Available from www.NQF.org.za (accessed on 13'th September 2011).

Kizito, R. 2006. Progressio: The Future Is Not So Bleak: Challenges With Recognition of Prior Learning (Rpl) Systems and Processes at the University of South Africa (Unisa). Progressio 28 (1 \& 2). Available from Http://www.Unisa.ac.za.Default.asp?cmd (accessed on 20 $0^{\text {th }}$ October 2011).

Klenowski, V. 2002. Developing portfolios for learning and assessment: Processes and principles. Routledge. http://books.google.co.za/books/about/Developing_Portfolios_for_Learning_and_A.html?id=pMMNAAAAQAAJ\&redir_esc=y. (accessed $11^{\text {th }}$ October 2011).

Kumar, R. 1999. Research Methodology: A Step By Step Guide for Beginners. London: Sage Publications.

Maboye, M. 2011. Understanding Recognition of Prior Learning (RPL) in the Context of organised labour: Opportunities and Challenges. South African Democratic Nurses Union (SADNU). A Paper Presented at the National RPL Conference: Bridging and Expanding Existing Islands of Excellent Practice. 23 - 25 February 2011. Available from: Http://www.saqa.org.za/docs/events/2011 /RPL_conf/posters/mosidi.pdf (accessed on 3rd September 2011).

Maree, K. 2007. First steps in research. Pretoria: Van Schaik's Publishers.

Moore, A. \& Van Rooyen, L. 2002. Recognition of Prior Learning as an integral Component of Competence-Based Assessment In South Africa. South African Journal of Education, 22(4):293-296.

Neuman, W. 2006. Social Research Methods: Qualitative and Quantitative Approaches. (6th Ed). USA: Pearson.

Newman, I. \& Benz, C.R. 1998. Qualitative-Quantitative Research Methodology: Exploring the Interactive Continuum. Southern Illinois University. USA: Cataloging-in-publication data.

Republic of South African.1995. South African Qualifications Act, Act No. 58 of 1995. Government Gazette, 364, No 1675.

Republic of South Africa. 1997. South African Qualifications Act, Act No. 58 of 1997. Government Gazette, Vol 1, No 1 May/June 1997.

SAQA. 2002. The Recognition of Prior Learning in the Context of the South African National Qualifications Framework. Available from Http://www.saqa.org.za/docs/policy/rpl01.pdf (accessed).

SAQA. 2002. Recognition of Prior Learning on the NQF: Readings on Purpose. Reading 1a. Extract from Recognition of Prior Learning in the Context of the South African NQF. Available from: http://www.saqa.org.za/docs/events/2011/rpl_conf/index.php ?include=presentations.html. (accessed 3rd November 2011).

SAQA. 2004. Criteria and Guidelines for the Implementation of The Recognition of Prior Learning, Discussion Document. Government Gazette, Republic of South Africa Vol. 455 No. 24855. Available From http://www.saqa.org.za/show.asp?id=986 (accessed 16th September 2010).

SAQA. 2011. National RPL Conference: Bridging and Expanding Existing Islands of Excellent Practice. 23 - 25 February 2011. Available from http://www.saqa.org.za/docs/events/2011/rpl_conf/index.php?include=presentations.html (accessed 3 rd September 2011).

Werquin, P. 2010. Recognition of Non-Formal and Informal Learning: Country Practices. OECD. Available From: http://www.oecd.org leducation/highereducationandadultlearning/44600408.pdfon (accessed 19th August 2011).

Woods, P. 2006. Quantitative Methods In Education Research. University of Plymouth. Available from: http://www.edu.plymouth.ac.uk /resined/quantitative/quanthme.htm. (accessed on $26^{\text {th }}$ October 2011). 
